\title{
Reflections on Professional Ethics Education in College Journalism Jing Zuo
}

Beijing Institute of Graphic Communication, Beijing 102600

\begin{abstract}
In recent years, the phenomenon of anomie in our country has occurred frequently, so that we have to reflect on the professional conduct of the press. University journalism ethics education is the first cornerstone of journalists to establish the professional ethics of journalism, and it is increasingly important to strengthen the professional ethics education in colleges and universities. The teaching contents should focus on cultivating critical thinking, and in terms of teaching methods, more situational teaching and debate teaching should be introduced while enhancing communicating with the industry. Professional news ethics education should be throughout the entire university education of news.
\end{abstract}

Keywords: Journalism; Professional ethics; Education

\section{高校新闻学专业职业道德教育的审思}

\author{
左晶 \\ ( 北京印刷学院 北京 102600)
}

摘要: 近年来, 我国新闻失范现象频频发生, 让我们不得不反思新闻界的职业操守问题。高校新闻职业伦理教育是新闻 从业者树立新闻职业道德意识的第一块基石, 加强高校职业道德教育日显重要。加强职业道德的教育, 首先要明确教学理念, 树立新闻专业主义理念和职业化的教育理念。此外, 在教学内容上注重批判性思维的培养, 在教学方法上更多地引入情景式 教学和辩论式教学, 并加强和业界的沟通, 将新闻职业道德教育贯穿到整个大学新闻教育的始终。

关键词: 新闻学专业; 职业道德; 教育

中图分类号: G21 文摘标识码: A

引言

近年来，有偿新闻、新闻敲许等现象频发，让我们不得不反思新闻界的职业操守问题。相应的加强新 闻传播学类学生职业道德教育工作, 也日益重要。高校的新闻职业伦理教育, 可以说是为未来新闻从业者 树立职业道德意识的第一块基石，这块基石站得稳，新闻从业者在实践中才能立得牢。但目前我国的新闻 教育中, 技能教育远远重于职业道德教育。在就业压力很大的今天, 技能教育固然重要, 但如果忽视职业 道德教育, 则会让整个新闻行业陷入价值混乱的泥潭。高校新闻学专业作为培养新闻人才的摇篮, 在职业 道德教育方面仍有诸多地方需要完善。

\section{1. 我国高校对新闻职业道德教育重视不足}

近几年随着就业压力的增大，各高校新闻专业也更加注重培养 “上手快、多技能、新科技”的应 用型新闻人才。对有关新闻业务的课程较为重视, 学分较高, 而对新闻伦理和职业道德教育则认识不够, 课时设置较少, 学分较低, 容易使学生产生轻视心理。根据 2012 年暑期中国政法大学传播法研究中心进 行的 “国内传播规范课程设置情况调查问卷” 显示, 国内很多高校都开设了媒介伦理相关课程, 但是基本 都与媒介法规课程合并在一起上。其调查的 54 所高校中, 共开设 68 门与伦理相关的课程, 与传播法合并 授课的有 52 门, 单独开设 16 门, 合并上课的比例达到 76. 47\%。而且在实际授课时, 很多课堂都挤压 
了伦理内容的授课时间。如果是 36 学时的课, 分配给伦理课的时间大概只有 12 学时, 如果是 64 学时的 课, 伦理课的时间一般只有 24 学时。这种课时上的不足, 必然导致学生对新闻职业伦理的轻视。

西方国家在教育改革中, 均把德育改革提到关系国家命运的高度, 将伦理道德视为本科课程体系的重 要组成部分。在美国很多著名大学新闻传播学的核心课程中, 都特别重视新闻伦理、传播法律等课程。根 据中国政法大学传播法研究中心 2012 年对获得美国新闻传播教育评审委员会（ACE-JME）认证的 109 所 学校的抽样调查, 在等距抽样的 34 所高校中, 在本科与研究生阶段, 其新闻传播院系开设的传播伦理课 程共 58 门, 其中单独开设伦理课程的有 52 门 (占 $90 \%$ )。 ${ }^{[1]}$ 可见其对新闻伦理课程的重视程度。我国虽 然没有新闻伦理教育可以影响价值观的相关调研, 但是西方同行一直很关注新闻伦理教育是否能够以及如 何 “影响价值观” 的问题? 有关学者曾经进行过一系列的研究。如 2007 年, 科罗拉多州立大学教师帕特 里克 (Patrick) 对 2001-2003 年新入学的 106 名学生进行了课前、课后的测试, 发现学生在课后对新 闻职业价值 (公正、独立、透明和减少伤害等) 的排序和比重都发生了变化，大部分学生在课前认为的 “最 难的伦理选择” 在课后也有所改变一一课前有 $23 \%$ 的学生认为 “利益冲突” 是最难应对的伦理问题, 课后 这个数字是 $37 \%$; 而他们对减少伤害、身份透明等价值, 均较之前的排序位置有所提高。研究者认为: 这 一变化与课堂设置的内容及强调的重点呈正相关, 这些西方学者针对伦理课程能否影响价值观的研究表 明：价值观可以通过有效的 “课堂灌输 柔性渗入” 方法, 培训学生的职业价值观, 并使之成为学生内心 长期拥有的 “职业价值观”。因而高校新闻传播类课程在教学中, 要加强职业伦理道德教育, 在人材培养 的源头就对其职业道德起到把关责任。

\section{2. 新闻职业道德教育的教学理念不明确}

新闻教育要改革, 首先要改进新闻教育理念, 只有正确的理论指导才能确保实践的顺利进行。“大学 新闻教育的目标是什么? 我的回答是：应该定在改进和提升整个社会的新闻工作的水准上，使全社会因有 高水平的新闻服务而受益。更重要的是, 要教育学生认识新闻工作对社会的责任和价值。” ${ }^{[2]}$ 基于此我认 为高校新闻职业伦理教育应明确如下教育理念。

\section{1 新闻专业主义的教育理念}

“专业主义”, 我们特指从事一种工作必须特定的专业技能、行为规范和评判标准, 而这些又必须经 过专门的训练才能获取, 并为从业者所共用。 ${ }^{[3]}$ 新闻专业主义是一种理想的新闻业的职业标准、态度和行 为。陆华和潘忠党对西方新闻专业主义理念作了系统的梳理, 并提出了新闻专业主义的基本内核：(1)传媒 是社会的公器，新闻工作必须服务于公众利益，而不是仅仅服务于任何政治或经济利益集团; (2) 新闻从 业者是社会的观察者、事实的报道者，而不是某一利益集团的宣传员；（3）他们是信息流通的 “把关人”， 采纳的基准是以中产阶级为主体的主流社会的价值观念，而不是政治、经济利益冲突的参与者或鼓动者; (4) 他们以实证科学的理性标准评判事实的真伪, 服从于事实这一最高权威, 而不是臣服于任何政治权力 或经济势力; (5)他们受制于建立在上述原则之上的专业规范, 接受专业社区的自律, 而不接受在此之外 的任何权力或权威的控制。这五条原则对新闻专业主义做出了相对明晰的判断。由于种种原因, 来自西方 的新闻专业主义理念与我国的新闻实践还存在很大距离。但是, 随着我国政治体制改革的深化, 新闻媒体 作为社会公器的功能日益受到重视, 逐渐从过度的政治功能向民众知情、表达、监督、参与民主政治的载 体转变。从本质上说, 一个国家的新闻是民主的事情, “大众传媒是公民表达权与知情权得以实现的重要 
载体, 没有媒体的参与, 公众的知情权、表达权, 乃至参与权、监督权都无法落到实处, 所谓的民主权利 也就失去了保障; 同时, 如果公众的知情权和表达权不能在媒体上得到真正贯彻, 新闻也就失去了其蓬勃 发展的根基与生命力 ${ }^{[4]}$. 按照新闻专业主义的职业标准, 高校在新闻教育也要明确专业主义的教育理念。失 却了新闻专业主义理念，整个新闻学教育就会失去灵魂，成为职业技能训练的基地。

高校进行新闻专业主义教育, 首先要将专业主义精神贯穿到新闻学主要课程中, 无论是理论课还是实 践课, 都要贯穿新闻专业主义的理念, 让学生在学校学习期间, 心中埋下专业主义的种子。其次专业主义 教育也要和我国具体的媒介环境相结合, 而不能分离。理想和现实可以有一定距离, 但是不能太远, 否则 学生在走向社会之后, 过大的反差会让他们迷惑, 甚至会将大学所树立的新闻理想全盘否定。

\section{2 新闻职业化的教育理念}

我国学者吴廷俊教授认为，所谓新闻教育的职业化，即以培养满足新闻实务工作需求的人才为出发点 进行教育活动, 包括课程设置, 内容选择和教学环节的安排等等。如果说新闻专业主义教育更加注重新闻 工作者应该具有的职业操守和社会责任意识, 那么职业化教育则在专业主义的引领下, 更为注重新闻职业 技能的培养。其实, 高校新闻教育的核心问题也就是这两部分, 即专业主义精神的培养和职业技能的训练。

高校的新闻教育应该全力服务于新闻事业，必须要有很强的职业导向。首先新闻学的教学目的就是培 养合格的职业化的新闻人才, 一直以来采访、编辑等业务课程都是新闻学专业最重要的课程, 学生要通过 课堂学习以及实践去掌握这些新闻业务的基本技能。美国新闻学专业著名的大学, 如哥伦比亚大学新闻学 院, 西北大学麦迪尔新闻学院, 密苏里大学新闻学院, 以及加州大学伯克力分校等都坚守职业化原则, 在 课程设置中, 将基本的教育采、写、编、评放在了最主要的位置, 他们认为, 新闻教育无论怎样发展, 职 业化教育仍然是基础, 仍然是新闻工作的核心。同时, 通过满足市场的需求来调节新闻教育的内容和体制, 也是职业化教育理念在传媒迅速发展的时代的必然要求。

这里我们要明确，新闻职业化教育和新闻专业主义教育并不矛盾，一个媒体从业人员如果没有一定的 伦理和理论素养, 便不能理性严谨地把握好的采访、编辑、发表过程中的行为尺度, 便不能真正知晓作为 一名新闻媒体专业人员的社会地位，以及作为专门进行传播的职业的意义和价值。

\section{3. 新闻职业道德教育教学内容和方法亟需改进}

考察新闻伦理学的教材, 可以发现多数教材偏重于学理的论述和道德原则规范的阐释, 新闻伦理课程 在教学中也经常会演变为一种道德说教, 或纠缠于理论阐释不能自拔。新闻伦理学本身是一门具有批判性、 反思性的课程, “新闻伦理是新闻工作者在其专业领域内对是非或适当与否下判断的良心尺度。” ${ }^{[5]}$ 批判性 思维的培养是新闻伦理课程的重点。新闻工作者依据什么道德标准选择新闻, 这是新闻道德实践中的核心 问题, 同样也是新闻伦理学中最基本的问题。因而在新闻伦理教育教学中, “必须学习如何正确处理在新 闻活动中发生的伦理问题, 必须学习在合乎道德的正当新闻行为与不合乎道德的不正当新闻行为之间作出 理性的抉择, 或在若干可能一定程度上都合乎道德的新闻行为中挑选出更加合乎道德的一个或几个, 必须 重视学生个体的主体地位并设法让学生学会自主进行道德判断。” ${ }^{[6]}$

在教学方式上, 应该更多地引入情景式教学和辩论式教学, 将生活实践中发生的问题提出来, 让学生思 考并展开辩论。设法使学生能够自主进行道德判断, 从而具有批判性思考和解决问题的能力。

此外, 学界和业界的有效沟通也是新闻伦理课程必不可少的环节。在新闻伦理课堂中, 请经验丰富的 
新闻从业人员来向学子们展现真实的新闻生态和伦理困境等, 无疑是一种有效的教育方式。北京市近几年 推行的媒体和高校之间互派人员挂职锻炼的活动，打通了学界和业界之间的隔阂，教师在媒体的挂职锻炼 使教师在课堂上不再只是纸上谈兵，而媒体人员在高校的挂职则让一线新闻工作者有机会把他们的经验传 授给新闻学子。大大提高了新闻学子的学习效果。

\section{4. 结语}

多年来, 我国新闻教育中职业道德教育是一个很大的缺失, 这直接导致新闻从业者社会责任意识淡薄, 而新闻传播教育的最终使命是培养社会责任感。美国南加州大学安伯伦格传播学院新闻系主任迈克・帕克 斯教授强调: 新闻教育的任务是把学生培养成优秀传媒工作者, 有职业伦理的记者, 新闻作品必须确保陈 述事实、准确、真实、公平和富有同情心。 ${ }^{[7]}$ 因而, 我们必须强化职业道德教育, 除了在课程中切实加入 新闻道德和新闻伦理的课程, 还要明确新闻职业道德教育的教育理念, 向学生强调新闻专业主义精神和理 想。在教学方法上也要理论联系实际, 和业界多多接触, 并将新闻职业道德教育贯穿到整个大学新闻教育 的始终。

\section{致谢}

基金项目: 北京印刷学院校级重点项目 “新媒体背景下新闻失范现象研究——以典型案例为切入进行 研究” (20190116002/001)

\section{Acknowledgement}

Fund project: Beijing Institute Of Graphic Communication's key project "Research into news anomie phenomenon under the new background of media- study from typical case" (20190116002/001)

\section{参考文献:}

[1] 阴卫之.传播伦理学教育理念、思路与方法 [J]. 新闻与写作, 2014, (5).

[2] 邓炘炘. 面对时代挑战的大学新闻教育——与南加大新闻系主任帕克斯教授谈新闻教育 [J]. 中国记者, 2008, (2).

[3] 陆晔、潘忠党.成名的想象:社会转型过程中新闻从业者的专业主义话语建构 [J]. 新闻学研究, 2002, (71).

[4] 李良荣, 张春华. 论知情权与表达权一一一兼论中国新一轮新闻改革 [J]. 现代传播, 2008, (4)

[5] 马骥伸. 新闻伦理 [M]. 台湾三民出版, 1997:3.

[6] 谭平剑. 试论我国新闻伦理教育目标与教学内容的重构 [J].传媒观察, 2011, (1).

[7] 钟新, 周树华. 新闻学院的吸引力在于职业教育——专访美国南加州大学安伦伯格传播学院新闻系主任迈克・帕克 斯教授.传媒镜鉴[M]. 中国传媒大学出版社, 2006:216.

\section{References:}

[1] Yin Weizhi, Communication ethics education concept, ideas and methods [J]. News and Writing, 2014, (5).

[2] Deng Xinxin. University journalism in the face of the challenges of the times [J]. Chinese journalists, 2008, (2).

[3] Lu Ye, Pan Zhongguo. Fame of Imagination: Construction of Professionalist Discourse of Journalists in the Process of Social Transformation [J]. Journal of Journalism Studies, 2002, (71). 
[4] Li Liangrong, Zhang Chunhua. On the Right to Know and Expression - Also on China's New News Reform [J]. Modern Communication, 2008, (4)

[5] Ma Yijie. News ethics [M]. Taiwan published three people, 1997: 3.

[6] Tan Pingjian. Discussion on the Reconstruction of News Ethic Education Goal and Teaching Content in China [J]. Journal of Media, 2011, (1).

[7] Zhong Xinhua, Zhou Shuhua. The attraction of journalism is vocational education [M]. China Communication University Press, 2006: 216. 